\title{
Using Anti-Cancer Agents during the Post-Partum Period: Not that Simple
}

\author{
Olivier Mir ${ }^{a, b}$ Paul Berveiller ${ }^{b} \quad$ Raphaël Serreau ${ }^{b, c}$
}

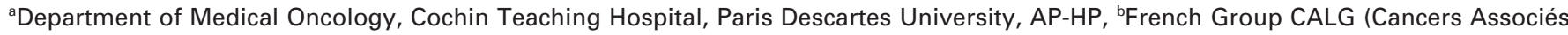
à La Grossesse), 'Clinical Research Unit, Cochin Teaching Hospital, Paris Descartes University, AP-HP, Paris, France

The diagnosis of a malignancy during pregnancy is a complex issue, the caregivers aiming to balance maternal optimal treatment and fetal well-being. Although a number of reports indicate limited short-term toxicities of selected cytotoxics during the third trimester of pregnancy [1-3], little is known on the pharmacokinetics of anti-cancer agents during pregnancy, and potential long-term toxicities cannot be excluded with the use of DNA damaging agents [4].

Hence, whenever possible, it is commonly admitted that chemotherapy should be postponed until after delivery in patients diagnosed with malignancies during the last weeks of pregnancy. However, the use of anti-cancer agents in the immediate postpartum period is also challenging because pharmacological changes that occur during pregnancy can preclude optimal drug dosing. For instance, the activity of CYP3A4 is increased by 50 $100 \%$ during the third trimester of pregnancy [5] possibly resulting in an altered clearance of drugs metabolized by this enzyme, such as taxanes, ifosfamide and doxorubicin. However, these changes appear to have regressed 6-10 weeks after delivery [6].

As well, albumin and alpha- 1 acid glycoprotein levels decrease during the course of pregnancy, potentially leading to decreased plasma protein binding, and enhanced pharmacodynamic effects due to an increased free drug fraction [7]. Unfortunately, it is unclear whether these changes remain clinically significant in the post-partum setting. A majority of studies evaluating pregnancyassociated pharmacological changes use patients over 6 weeks post-partum as controls [5], and little is known on pharmaco-

\section{References}

1 Mir O, Berveiller P, Goffinet F, Treluyer JM, Serreau R, Goldwasser F, Rouzier R: Taxanes for breast cancer during pregnancy: a systematic review. Ann Oncol 2010;21:425-426.

2 Mir O, Berveiller P, Ropert S, Goffinet F, Pons G, Treluyer JM, Goldwasser F: Emerging therapeutic options for breast cancer chemotherapy during pregnancy. Ann Oncol 2008;19:607-613.

3 Stensheim H: Malignant melanoma and pregnancy. Onkologie 2009;32:715-716.

4 Mir O, Berveiller P, Ropert S, Goffinet F, Goldwasser F: Use of platinum derivatives during pregnancy. Cancer 2008;113:3069-3074. kinetic and pharmacodynamic changes during the first month following delivery.

In the present issue of ONKOLOGIE, Savvari et al. [8] report on a patient diagnosed with a Burkitt's lymphoma with bilateral breast involvement. The diagnosis was made shortly after delivery, and the treatment was initiated during the next month. Despite disease-related liver dysfunction, the authors report a successful use of a multi-drug regimen, with adapted doses and omission of methotrexate. The diagnosis of breast malignancies during pregnancy is often difficult, and a delay in diagnosis is frequent [9]. For instance, in one series from the M.D. Anderson Cancer Center [10], the average delay in diagnosis in pregnant women was 8.2 months compared to 1.9 months in non-pregnant women. Burkitt's lymphomas associated with pregnancy have a dismal prognosis, in particular when the diagnosis is made in early pregnancy, thereby making difficult the use of optimal dose-dense treatments [11].

Finally, the use of anti-cancer agents during the post-partum period ( $<6$ weeks after delivery) may be as challenging as their use during pregnancy. Although the fetal risk is by definition absent in this setting, the optimal maternal treatment should be tailored to the pharmacological properties of the drugs employed. Further studies in breast cancer patients receiving taxanes and anthracyclines in this period are ongoing, and may provide additional information in order to better handle anti-cancer agents in patients with pregnancy-associated malignancies.

\section{Conflict of Interest}

The authors declare no conflicts of interest.
5 Anderson GD: Pregnancy-induced changes in pharmacokinetics: A mechanistic-based approach. Clin Pharmacokinet 2005;44:989-1008.

6 Hebert MF, Easterling TR, Kirby B, Carr DB, Buchanan ML, Rutherford T, Thummel KE, Fishbein DP, Unadkat JD: Effects of pregnancy on cyp3a and p-glycoprotein activities as measured by disposition of midazolam and digoxin: A University of Washington specialized center of research study. Clin Pharmacol Ther 2008;84:248-253.

7 Pavek P, Ceckova M, Staud F: Variation of drug kinetics in pregnancy. Curr Drug Metab 2009; 10:520-529.
8 Savvari P, Matsouka C, Barbaroussi D, Christoulas D, Nikitas N, Dimopoulos MA, Papadimitriou CA: Burkitt lymphoma in pregnancy with bilateral breast involvement: a case report with review of the literature. Onkologie 2010:33 DOI: 10.1159/000317344.

9 Saunders C, Ives A, Puckridge P, Semmens J: Delays in diagnosing breast cancer--the impact of concurrent pregnancy and lactation. Aust $\mathrm{N}$ Z J Obstet Gynaecol 2002;42:573-575.

10 Theriault RL, Stallings CB, Buzdar AU: Pregnancy and breast cancer: clinical and legal issues. Am J Clin Oncol 1992;15:535-539.

11 Peterson C, Lester DR, Jr., Sanger W: Burkitt's lymphoma in early pregnancy. J Clin Oncol 2010;28:e136-138.

\section{KARGER}

Fax +497614520714

Information@Karger.de

www.karger.com (c) 2010 S. Karger GmbH, Freiburg

Accessible online at:

www.karger.com/onk
Olivier Mir, MD, MSc, MPH

Department of Medical Oncology

Cochin Teaching Hospital

27, rue du faubourg Saint Jacques, 75014 Paris, France

Tel. +33 158 411-439, Fax -434

olivier.mir@cch.aphp.fr 